\title{
Laboratory full-scale rock bolt testing: Analysis of recent results
}

\author{
S.A. Hagen'1, T. Larsen'1, A. Berghorst ${ }^{2}$, and G. Knox ${ }^{3}$ \\ 1SINTEF AS, Norway \\ ${ }^{2}$ New Concept Mining Canada \\ ${ }^{3} \mathrm{New}$ Concept Mining, South Africa
}

\begin{abstract}
Rock bolting is a method used for rock reinforcement in underground mining and tunnelling. There is a large variety of different types of rock bolts with different support functions. The behaviour of a rock bolt in a rock mass depends on the function and material of the bolt itself, combined with the mechanical properties of the rock mass, deformation capacity, strength and level of stress. Testing of rock bolts in full-scale laboratorycontrolled conditions is therefore of great importance. At the rock mechanics laboratory of SINTEF and Norwegian University of Science and Technology (NTNU) in Trondheim, a rock bolt test rig has been developed for full-scale testing for pull, shear and combination pull-shear tests. This paper describes the principles behind this quasi-static full-scale testing and includes the results and analyses of recent tests performed on different types of rock bolts. It also discusses the applicability of the test rig for rock bolt selection and rock support design.
\end{abstract}

\section{INTRODUCTION}

At the rock mechanics laboratory of SINTEF and NTNU in Trondheim (Norway), a rock bolt test rig has been developed for full-scale testing for pull, shear and combination pull-shear tests. The rock bolt test rig was developed in 1995, in conjunction with Gisle Stjern's doctoral thesis. The test rig was financed by research funds and also by Ørsta AS, one of the leading suppliers of rock bolts. The purpose of Stjern's work was to investigate the mechanical performance of different rock bolts when subjected to different loading conditions. The aim was to be able to simplify the choice of bolt type and design for a given application (Stjern, 1995). Subsequently, the bolt test rig has been used for several masters and doctoral research projects as well as for commissioned testing. More than 35 different bolt types have been tested in the full-scale test rig. The rock mechanics laboratory at SINTEF/NTNU has gained valuable experience and significant knowledge as a result of these test programmes.

An important element of this test facility is that it allows us, in a controlled and fully monitored way, to pull/shear the bolts to loads beyond their capacity. This includes testing the capacity of the fixation system using fully-grouted/resin- grouted bolts or other methods. Thus, it can also be used as a system test.

SINTEF was commissioned by New Concept Mining (NCM) to test various types of bolts in the rock mechanics laboratory from 2016 to 2018. The purpose of the tests was to certify the bolts for use in specific mines and also certify their properties in the full-scale test-rig. Some of the results from these tests will be presented as examples of test results from the full-scale rock bolt test rig. These results will be compared to other standardised tests performed elsewhere on the same bolts. 


\section{TEST ARRANGEMENT}

\section{Test apparatus - SINTEF/NTNU rock bolt test rig}

The SINTEF/NTNU rock bolt test rig consists of a rigid frame with two concrete cubic blocks (See Figure 1 and Figure 2). The two concrete blocks can be moved relative to each other in two different directions in the horizontal plane. This is used to simulate shear and tensile loads on the test bolts. The movement is shown in Figure 3. Each block measures $0.95 \mathrm{~m}$ along each side. To simulate hard rock conditions and secure strong fixation points, both blocks are cast from high strength concrete (UCS $\approx 120 \mathrm{MPa}$ ). The blocks are cured for at least 28 days after casting and before testing. The test rig has a loading capacity of $600 \mathrm{kN}$ in tension and $500 \mathrm{kN}$ in shear. The hydraulic loading system consists of two hollow jacks (2 $\mathrm{x} 300 \mathrm{kN}$ ) pulling the tensile cube, and one ram jack pushing the shear cube. The hydraulic pressure cylinders have a maximum stroke length of $250 \mathrm{~mm}$ in tension and $150 \mathrm{~mm}$ in shear.

Roller bearings are installed between the blocks and the frame in order to guide the blocks and minimize frictional resistance. The roller bearings and frame also minimise rotation of the concrete blocks during the test. The test rig is instrumented with extensometers, load cells and hydraulic pressure transducers. The data from these is used to generate the load-deformation characteristics of each test. The practical accuracy of the readout is $1 \mathrm{kN}$ in load and $1 \mathrm{~mm}$ in deformation. Strain gauge measurement can be used to get detailed information of the load distribution along the bolt during the test.

This test will be referred to as the SINTEF/NTNU shear or pull test in the following sections.

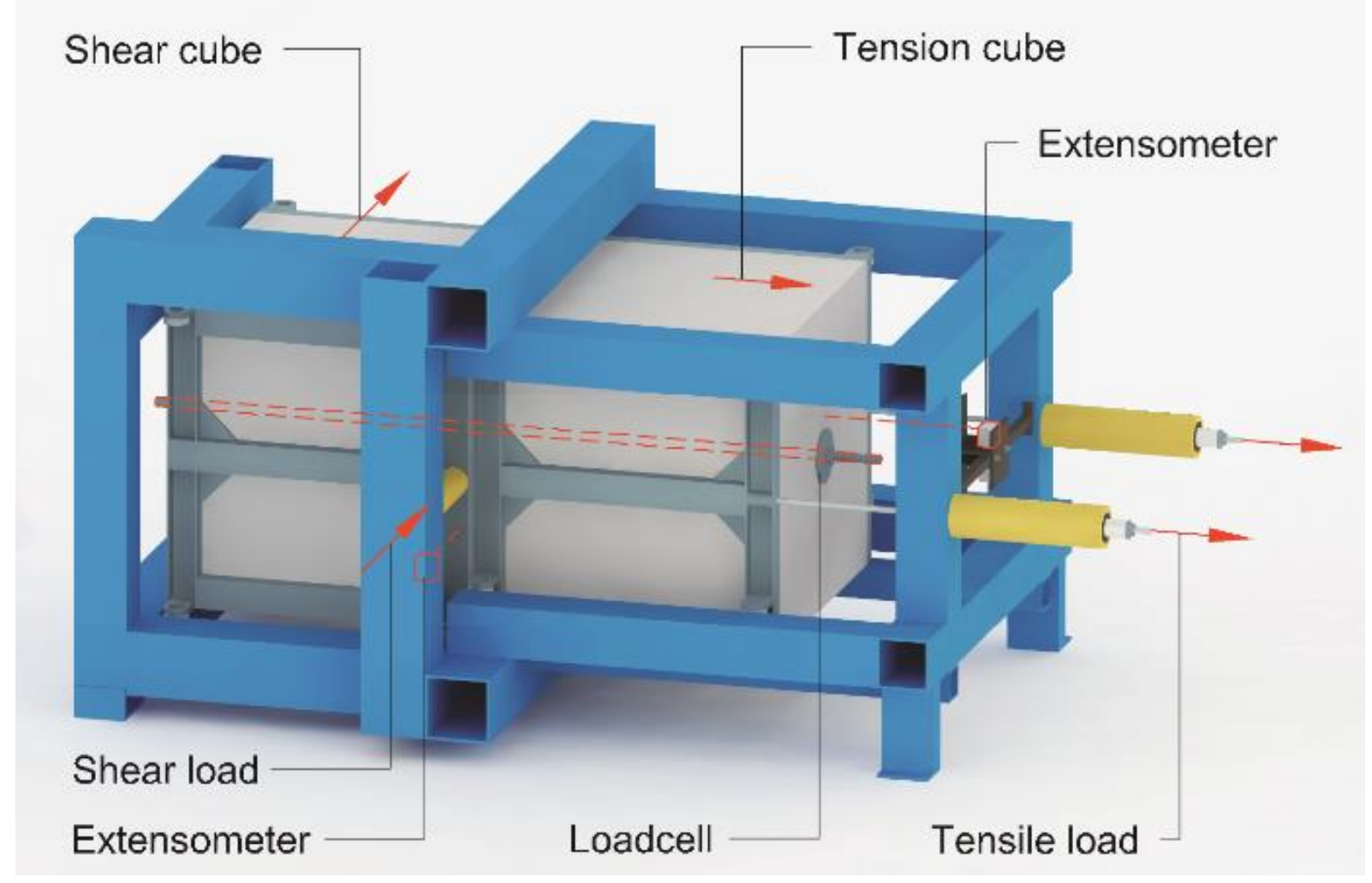

Figure 1. Outline of the test rig. Extensometers are placed on rock bolt head, tension cube and shear cube. Load cell is placed on bolt head. Concrete blocks (in grey) are located inside the blue frame of the test rig. 


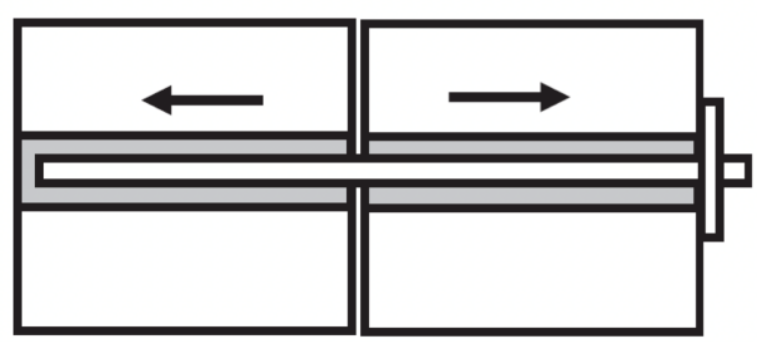

(a) Pull test

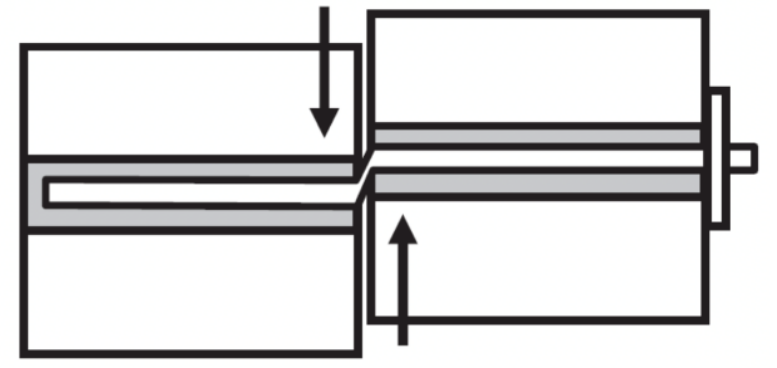

(b) Shear test.

Figure 2. Diagrams illustrating the principles of rock bolt static pull and shear tests $(L i, 2010)$

\section{Test procedure}

\section{Drilling holes for bolt installation}

Before the cured blocks are installed in the test rig, the rock bolt test installation boreholes are drilled to the same diameter as used in the field. Figure 3 shows percussive drilling of the test boreholes. It is important that the boreholes are correctly aligned in the concrete blocks, especially for correct installation of the rock bolts. Each pair of blocks can accommodate a maximum of 13 tests before boreholes are too close to the edge of the block for accurate testing. Holes that are near the edge of the block can only be used for pull tests to avoid failure of blocks. The hole diameter can be adjusted to the specifications of the rock bolt being tested. Typical borehole diameters are $33 \mathrm{~mm}$ and $48 \mathrm{~mm}$. The rock bolt length that can be accommodated is approximately $1.8 \mathrm{~m}-2.0 \mathrm{~m}$ to suit the geometry of the test rig and depending on the bolt type.

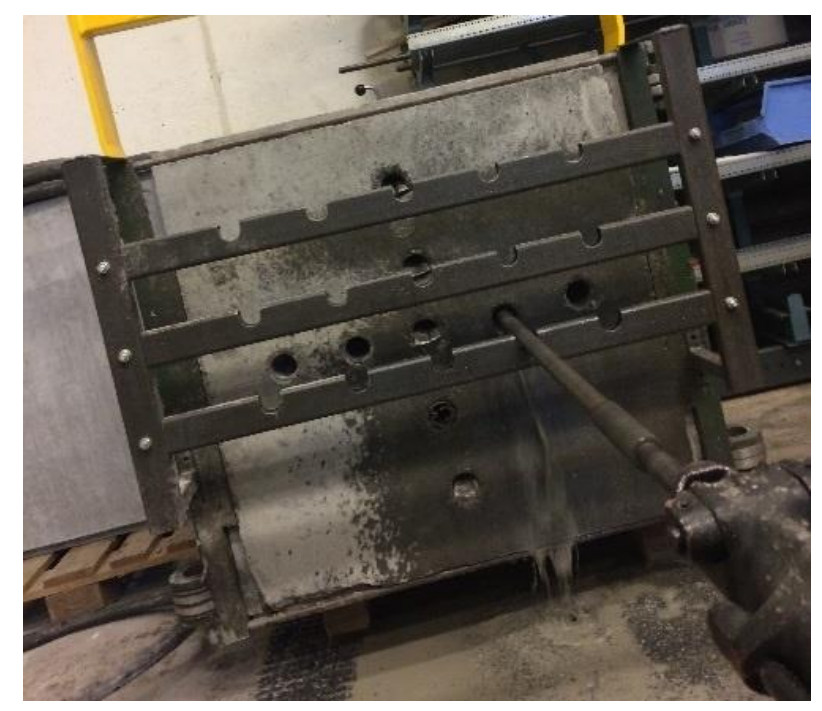

Figure 3. Drilling holes for testing.

Installing rock bolt

Figure 4 shows the principles for installing rock bolts in the concrete blocks. To simulate in-situ conditions, SINTEF/NTNU procedure requires that the bolts are tested with the same outfit as for normal installation. The two concrete blocks are inserted into the frame and the alignment of the drill holes for the specific test are checked. A hollow rubber gasket $(8 \mathrm{~mm}$ thick, $\varnothing 150 \mathrm{~mm}$ ) is placed directly over the drill hole, creating a seal when the two concrete blocks are pressed together. The seal will prevent cement mortar or resin from flowing between the concrete blocks, as well as creating a gap of approximately $5 \mathrm{~mm}$ between the concrete blocks. This gap between the concrete blocks minimises the influence of the joint shear resistance during a shear test. A constant load of $15 \mathrm{kN}-20 \mathrm{kN}$ compresses the concrete blocks during the installation of the rock bolt and the curing of the cement mortar or resin. Mixing and filling with grout is normally performed with ordinary field equipment. The drill hole needs 
to be plugged at the far end and grouting is performed carefully to ensure complete filling. Curing time and water-cement ratios are important factors regarding the installation and are carefully documented. As standard for cement mortar, a curing time of a minimum of 72 hours and a water-cement ratio of 0.32 are used. Other types of bolt anchoring can also be applied, such as mechanical anchoring and friction anchoring.

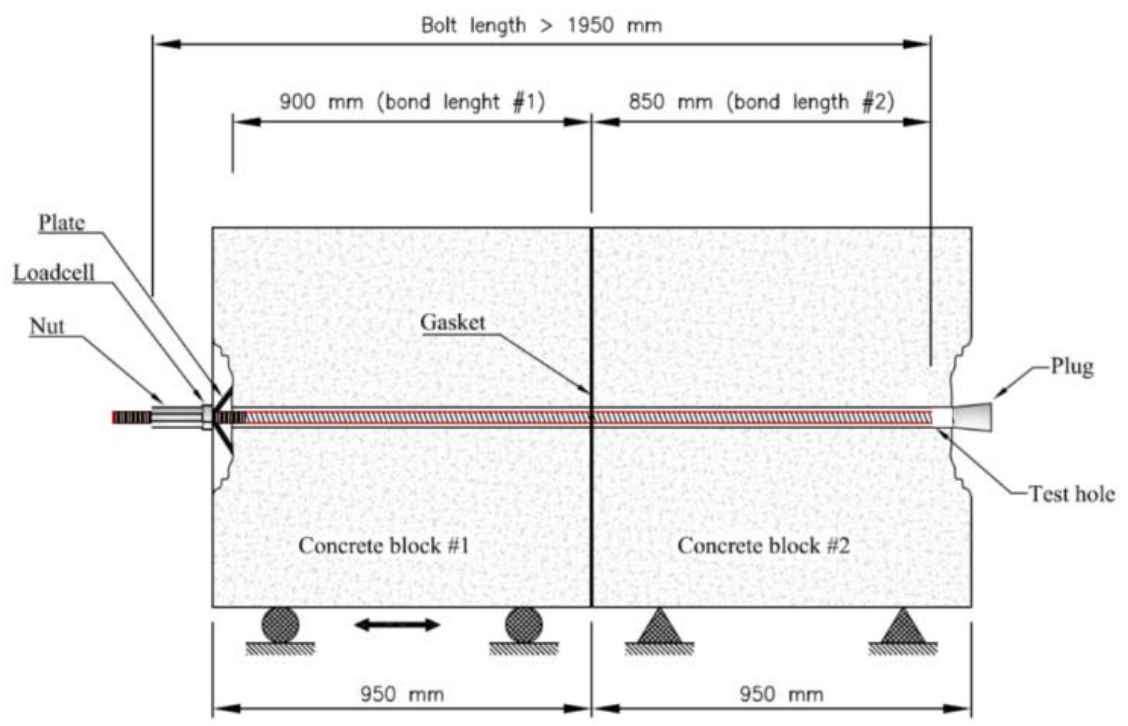

Figure 4. Layout of test setup when rock bolt is installed in concrete blocks, ready for testing. Sketch applies for shear and tension tests.

Testing of bolt performance

When the installation is complete, the testing will normally commence after 72 hours and the clamping force of $15-20 \mathrm{kN}$ is then removed. The rock bolt head is equipped with a load cell to measure the load transferred to the head of the rock bolt in the test. The nut of the bolt head is normally pretensioned to a tensile load of $5 \mathrm{kN}$ to insure good contact. Extensometers are mounted on the bolt and the concrete blocks to measure displacement. Before the test is conducted, the test rig hydraulic cylinders are pressurized to a $15 \mathrm{kN}$ load in the test direction (shear or pull) to remove any slack in the system. Testing is then performed with a constant deformation rate of approximately $30 \mathrm{~mm}$ per minute until failure. The datalogging rate is $5 \mathrm{~Hz}$ during the whole test. After testing, the failure of the bolt and bolt head is carefully inspected and documented with photos and comments.

\section{Test results}

Test results include: yield load, ultimate load and deformation; this is reported in tables with graphs and photos from the testing. Shear capacity of bolts is shown as applied shear load, including the shear resistance of the joint. Comments describe the type of failure and other conditions that could be of importance for the test results. Documented bolt performance is based on a minimum of three individual test runs for both shear and pull tests. Rock bolt behaviour can be classified as stiff, ductile and energy-absorbing from the point of view of bolt performance ( $\mathrm{Li}, 2010)$. Figure 5 shows typical test result graphs from the SINTEF/NTNU test rig for three different bolts subjected to shear and pull tests. 

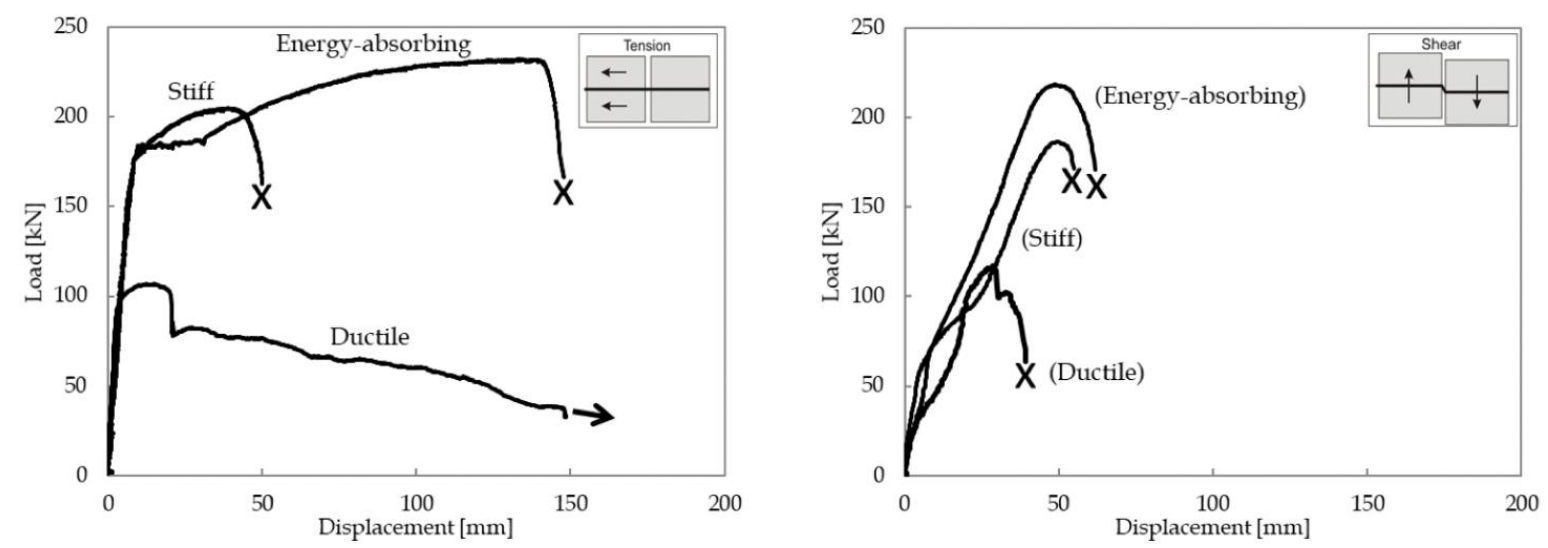

Figure 5. Performance of different rock bolts subjected to pull loading and shear loading, classified as stiff, ductile and energy-absorbing (Li, 2010).

\section{Test apparatus - Direct shear and tensile test}

Both the direct shear and pull test methods as described below are common industry testing methods. However, special tools and jigs were designed by New Concept Mining (NCM) for conducting their own tests. The tests were commissioned and performed at reputable testing centres, including the CSIR. The purpose of these tests was to attempt to quantify the performance of the rock bolts being tested. The results from the SINTEF/NTNU testing machine will be compared to the results obtained from some of the shear and pull tests on rock bolts. The pull test results were obtained by testing an entire rock bolt grouted inside a steel tube. This steel tube is cut in its mid-point. The assembly is fitted into a tensile testing machine and pulled until the rock bolt breaks. The data from these tests is logged and processed and presented in the following section. The layout of the pull test is shown in Figure 6.

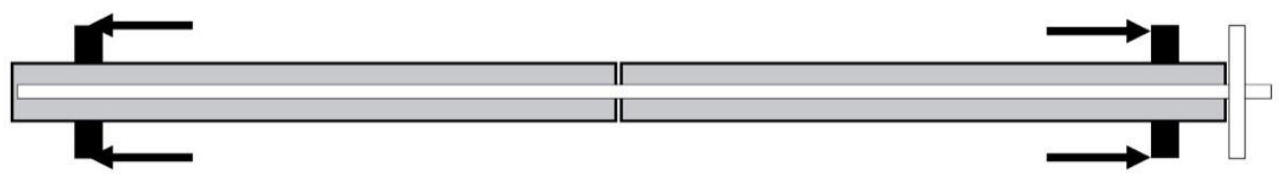

Figure 6. Pull test layout for the standard tensile test.

The standard shear testing involves grouting a portion of a rock bolt in a steel tube. This steel tube is cut in two places around its mid-point. This assembly is then fitted into a double shear testing jig as indicated in the Figure 7.

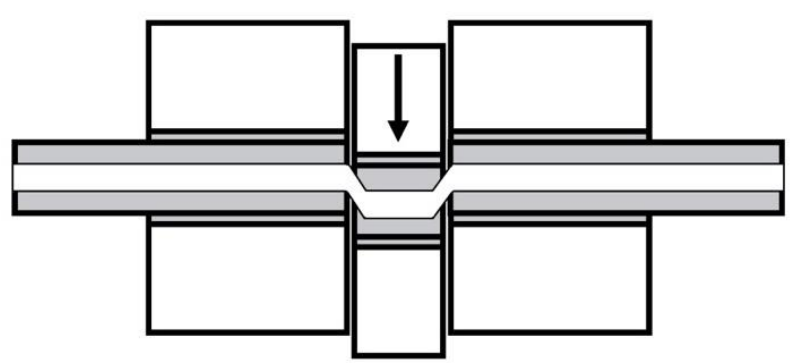

Figure 7. Double shear test layout for standard shear testing

The double shear test will induce a shear failure in two positions on the test sample, and therefore in order to quantify the single shear performance of the rock bolt, the load is halved. During this test the loading head travels at approximately $30 \mathrm{~mm}$ per minute. The test is designed so that the two outer 
components are supported while the middle portion moves downward. This test induces a double shearing action on the test sample. It should be noted that during this test the loaded sample is confined within the test jig.

These tests will be referred to as the standard shear or pull test in the following sections.

\section{Recent test results}

Results from recent tests undertaken at SINTEF/NTNU include data for the PAR1 and Hydrabolt manufactured by NCM. The results from the SINTEF/NTNU testing machine will be compared to the results obtained from standard pull and shear tests described above and on the same bolt types.

\section{Pull test grout anchored energy-absorbing rock bolt - PAR1 $20 \mathrm{~mm}$ bolt}

Figure 8 shows the PAR1 bolt. The PAR1 Bolt is an energy-absorbing rock bolt designed with a paddled yielding bar. This yielding bolt is designed for use in underground mines that experience squeezing ground and/or rock bursting. The design of the PAR1 Bolt is such that it can be used with a variety of encapsulated mediums, including cementitious grout and resin capsules. Installation was completed as per the abovementioned test procedure in $33 \mathrm{~mm}$ test holes drilled in the concrete blocks. The rock bolts were fully grouted with an NCM grout designed for use with rockbolts in high temperature mines. Testing was carried out after a minimum curing time of 48 hours.

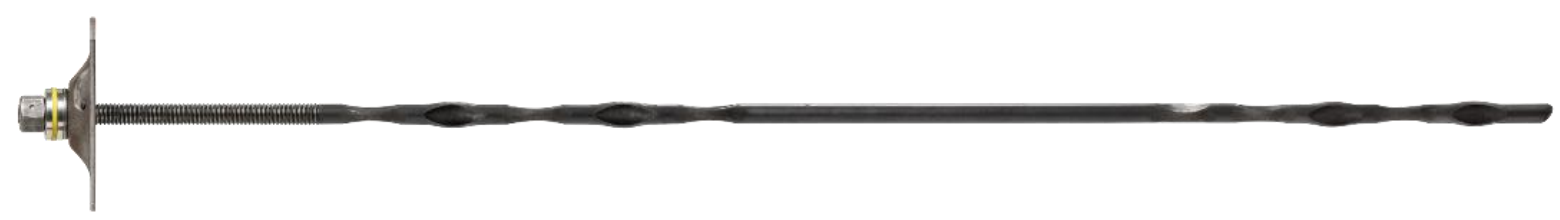

Figure 8. PAR1 energy-absorbing rock bolt (NCM).

Table I and Table II show pull test results for the two different methods, and load-displacement behaviours of the bolts are shown in Figure 9. For the SINTEF/NTNU pull test, the mean maximum load and displacement are $236 \mathrm{kN}$ and $164 \mathrm{~mm}$ respectively. For the standard pull test, the mean maximum load and displacement are $227 \mathrm{kN}$ and $160 \mathrm{~mm}$ respectively. Figure 10 shows the bolt pull test failure.

Table I. Test results pull test grouted anchored PAR1 20 mm energy-absorbing bolt (SINTEF, 2016).

\begin{tabular}{cccc}
\hline \multirow{2}{*}{ Test ID } & $\begin{array}{c}\text { Yielding load } \\
{[\mathrm{kN}]}\end{array}$ & $\begin{array}{c}\text { Maximum load } \\
{[\mathrm{kN}]}\end{array}$ & $\begin{array}{c}\text { Maximum displacement } \\
{[\mathrm{mm}]}\end{array}$ \\
\hline Test 1 (SINTEF) & 183 & 232 & 133 \\
Test 2 (SINTEF) & 180 & 238 & 153 \\
Test 2 (SINTEF) & 177 & 238 & 153 \\
\hline Mean & $\mathbf{1 8 0}$ & $\mathbf{2 3 6}$ & $\mathbf{1 6 4}$ \\
\hline
\end{tabular}


Table II. Pull test results for grouted PAR1 20 mm energy-absorbing bolts (CSIR, 2015). Test results displacement scaled as a function of loaded length*).

\begin{tabular}{cccc}
\hline \multirow{2}{*}{ Test ID } & Yielding load & Maximum load & Maximum displacement \\
& {$[\mathrm{kN}]$} & {$[\mathrm{kN}]$} & {$[\mathrm{mm}]$} \\
\hline Test 1 (Std. Shear) & N/A & 223 & 165 \\
Test 2 (Std. Shear) & N/A & 228 & 156 \\
Test 3 (Std. Shear) & N/A & 229 & 158 \\
\hline Mean & N/A & $\mathbf{2 2 7}$ & $\mathbf{1 6 0}$ \\
\hline
\end{tabular}

*) Standard test sample was longer than the SINTEF/NTNU sample. Therefore, the displacement for the Standard test has been scaled as a function of the loaded length of the samples from the SINTEF/NTNU test and the Standard test.

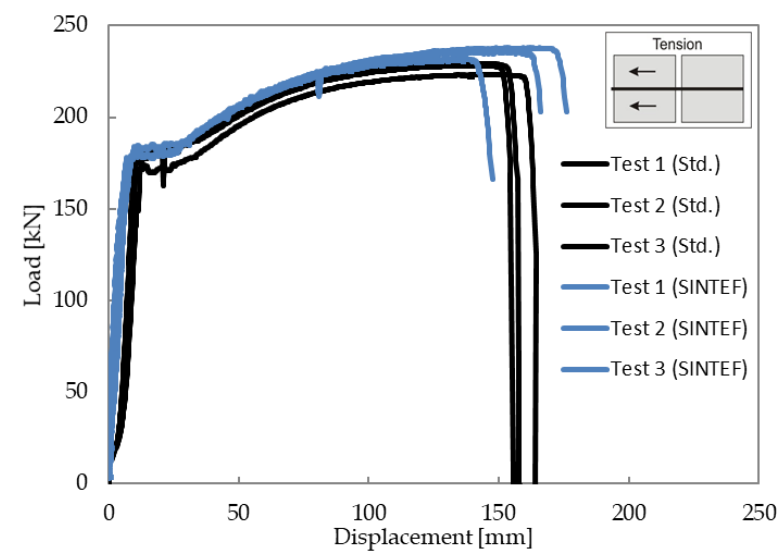

Figure 9. Comparison of pull test results for PAR1 $20 \mathrm{~mm}$ bolt, load displacement plot, for standard pull test and SINTEF/NTNU pull test*).
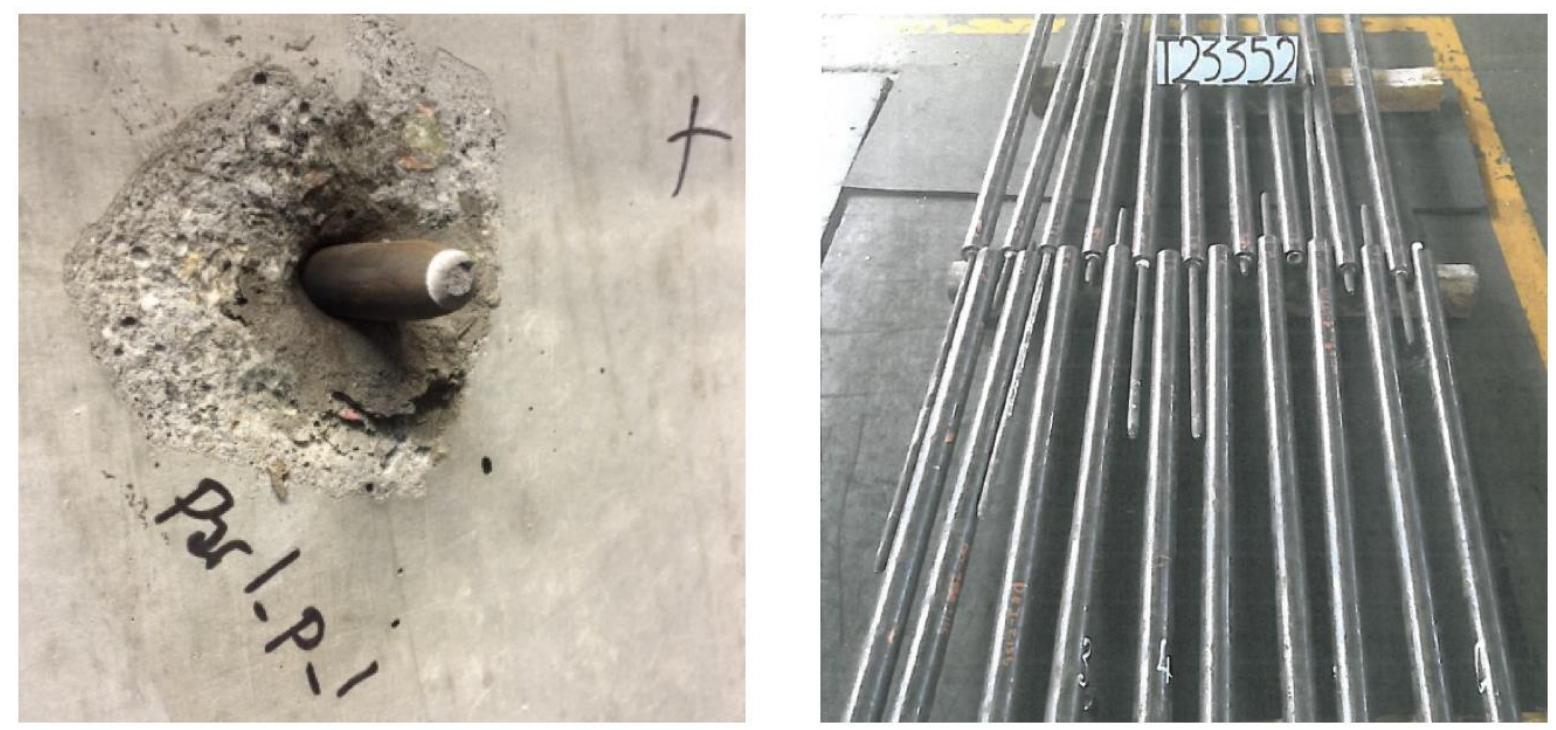

Figure 10. Post-test view of grouted PAR1 $20 \mathrm{~mm}$ rock bolt, SINTEF/NTNU pull test on the left (SINTEF, 2016) and the standard pull test on the right (CSIR, 2015). 
Shear test of grouted energy-absorbing rock bolt - PAR1 $25 \mathrm{~mm}$ bolt

This test was performed using a PAR1 $25 \mathrm{~mm}$ bolt (See Figure 8). The PAR1 $25 \mathrm{~mm}$ bolts that were submitted for shear testing are manufactured from high strain to failure steel. These rock bolts are drawn from a single batch of steel from a standard production line with no special treatment given during manufacturing. Installation was completed as per the abovementioned test procedure in $33 \mathrm{~mm}$ test holes drilled in the concrete blocks. The rock bolts were fully grouted with an NCM grout designed for use with rock bolts in hot mines. Testing was carried out after a minimum curing time of 48 hours.

Table III and Table IV show shear test results for the two different methods; load-displacement behaviours of the bolts are shown in Figure 11. For the SINTEF/NTNU shear test, the mean maximum load and displacement are $327 \mathrm{kN}$ and $59 \mathrm{~mm}$ respectively. For the direct shear test the mean maximum load and displacement are $271 \mathrm{kN}$ and $21 \mathrm{~mm}$ respectively. Figure 12 shows the bolt shear test failure.

Table III. SINTEF/NTNU shear test of grouted PAR1 25 mm energy-absorbing bolt (SINTEF, 2016)

\begin{tabular}{cccc}
\hline Test ID & $\begin{array}{c}\text { Yielding load } \\
{[\mathrm{kN}]}\end{array}$ & $\begin{array}{c}\text { Maximum load } \\
{[\mathrm{kN}]}\end{array}$ & $\begin{array}{c}\text { Maximum displacement } \\
{[\mathrm{mm}]}\end{array}$ \\
\hline Test 1 (SINTEF) & 96 & 325 & 56 \\
Test 2 (SINTEF) & 89 & 323 & 60 \\
Test 3 (SINTEF) & 89 & 333 & 60 \\
\hline Mean & $\mathbf{9 1}$ & $\mathbf{3 2 7}$ & $\mathbf{5 9}$ \\
\hline
\end{tabular}

Table IV. Test results for shear tests on grouted PAR1 25 mm energy-absorbing bolt (CSIR, 2016). Maximum load adjusted for 2 points of support (original maximum load divided by 2).

\begin{tabular}{cccc}
\hline \multirow{2}{*}{ Test ID } & Yielding load & Maximum load & Maximum displacement \\
& {$[\mathrm{kN}]$} & {$[\mathrm{kN}]$} & {$[\mathrm{mm}]$} \\
\hline Test 1 (Std. Shear) & N/A & 272 & 22 \\
Test 2 (Std. Shear) & N/A & 271 & 21 \\
Test 3 (Std. Shear) & N/A & 269 & 21 \\
Test 4 (Std. Shear) & N/A & 270 & 21 \\
Test 5 (Std. Shear) & N/A & 273 & 22 \\
\hline Mean & N/A & $\mathbf{2 7 1}$ & $\mathbf{2 1}$ \\
\hline
\end{tabular}




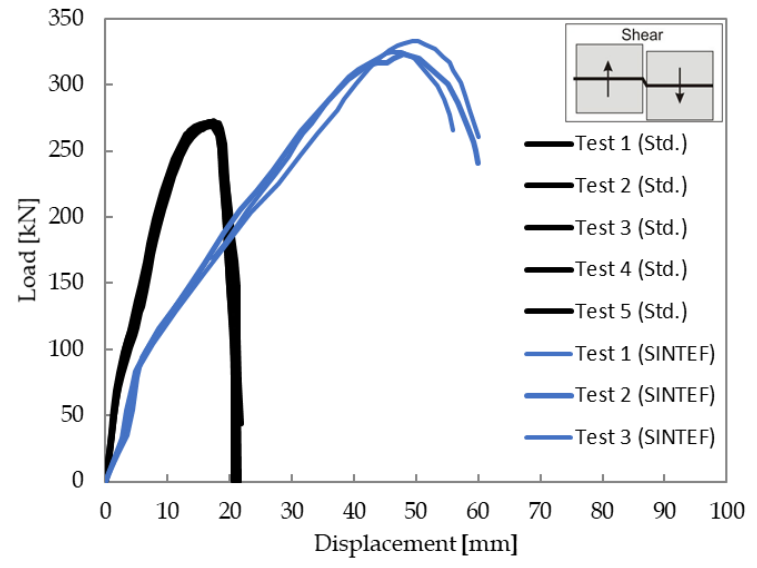

Figure 11. Comparison of shear test results for the PAR1 $25 \mathrm{~mm}$ bolt, load displacement plot, for standard shear test and SINTEF/NTNU shear test.
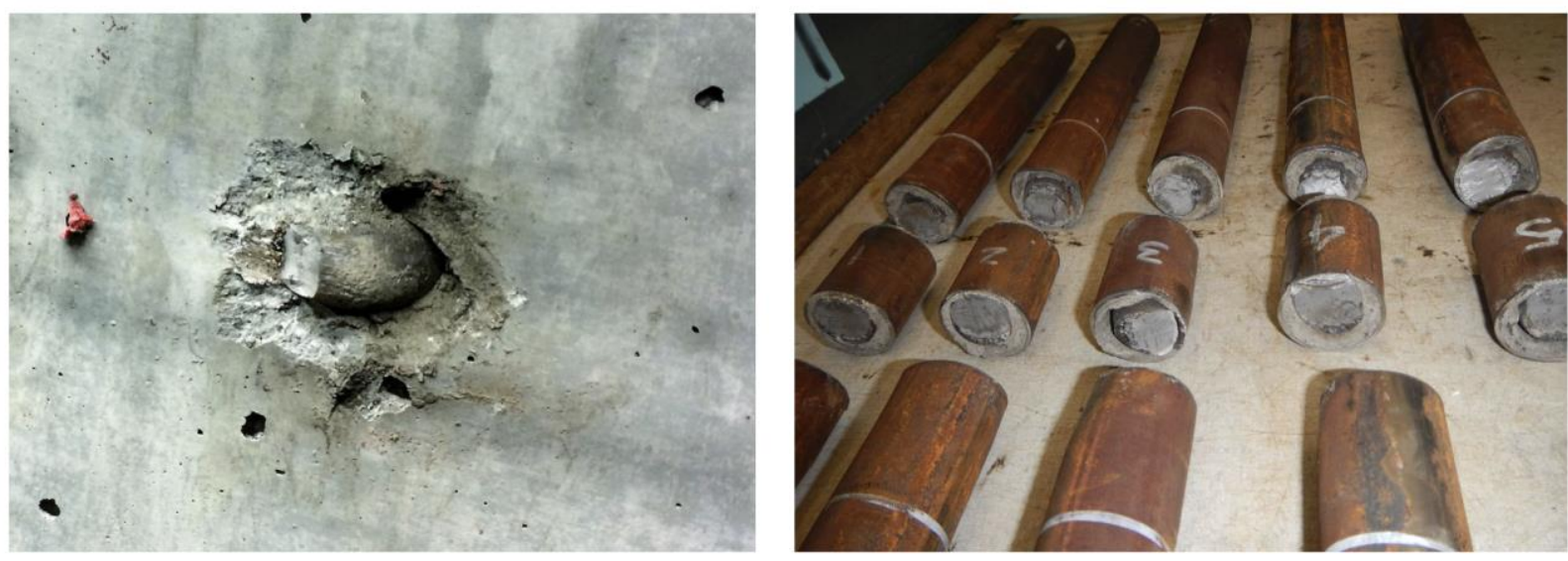

Figure 12. Post-test view of grouted PAR1 $20 \mathrm{~mm}$ rock bolt, SINTEF/NTNU shear test on the left (SINTEF, 2017) and the standard double shear test on the right (CSIR, 2016).

\section{Shear test inflatable bolt - Hydrabolt $29 \mathrm{~mm}$}

Figure 13 shows the $29 \mathrm{~mm}$ Hydrabolt. Hydrabolts used in these tests have an uninflated tube diameter of $29 \mathrm{~mm}$. The wall thickness of the tube is $2.0 \mathrm{~mm}$. This Hydrabolt is designed to be installed in a hole with a diameter of between $34 \mathrm{~mm}$ and $40 \mathrm{~mm}$. For the SINTEF/NTNU test method $37 \mathrm{~mm}$ holes were used. The bolt was installed with a water inflation pressure of 300 bar. Testing was carried out within 10 minutes after inflation.

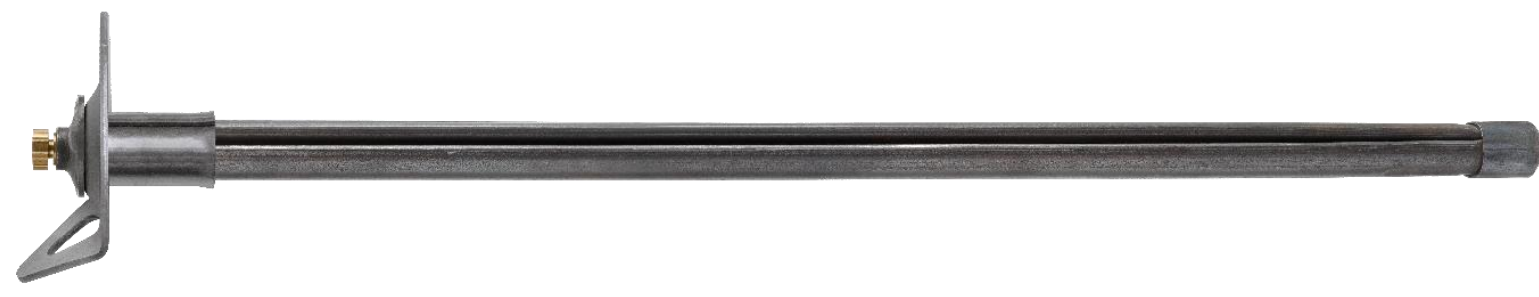

Figure 13. Inflatable bolt, Hydrabolt $29 \mathrm{~mm}$ 
Table V and Table VI show shear test results for the two different methods; load-displacement behaviours of the bolts are shown in Figure 19 and Figure 20. For the SINTEF/NTNU shear test, the mean maximum load and displacement are $119 \mathrm{kN}$ and $41 \mathrm{~mm}$ respectively. For the direct shear test, the mean maximum load and displacement are $60 \mathrm{kN}$ and $11 \mathrm{~mm}$ respectively. Figure 16 and Figure 17 show the bolt shear test failures.

Table V. Test results SINTEF/NTNU shear test Hydrabolt 29 mm inflatable bolt (SINTEF, 2017)

\begin{tabular}{cccc}
\hline \multirow{2}{*}{ Test ID } & $\begin{array}{c}\text { Yielding load } \\
{[\mathrm{kN}]}\end{array}$ & $\begin{array}{c}\text { Maximum load } \\
{[\mathrm{kN}]}\end{array}$ & $\begin{array}{c}\text { Maximum displacement } \\
{[\mathrm{mm}]}\end{array}$ \\
\hline Test 1 (SINTEF) & 43 & 119 & 41 \\
Test 2 (SINTEF) & 39 & 121 & 40 \\
Test 3 (SINTEF) & 42 & 117 & 42 \\
\hline Mean & $\mathbf{4 1}$ & $\mathbf{1 1 9}$ & $\mathbf{4 1}$ \\
\hline
\end{tabular}

Table VI. Shear test results Hydrabolt 29 mm inflatable bolt (CSIR, 2016) Maximum load halved for double shear

\begin{tabular}{cccc}
\hline \multirow{2}{*}{ Test ID } & Yielding load & Maximum load & Maximum displacement \\
& {$[\mathrm{kN}]$} & {$[\mathrm{kN}]$} & {$[\mathrm{mm}]$} \\
\hline Test 1 (Std. Shear) & N/A & 65 & 9 \\
Test 2 (Std. Shear) & N/A & 58 & 8 \\
Test 3 (Std. Shear) & N/A & 62 & 13 \\
Test 4 (Std. Shear) & N/A & 62 & 13 \\
Test 5 (Std. Shear) & N/A & 55 & 12 \\
\hline Mean & N/A & $\mathbf{6 0}$ & $\mathbf{1 1}$ \\
\hline
\end{tabular}

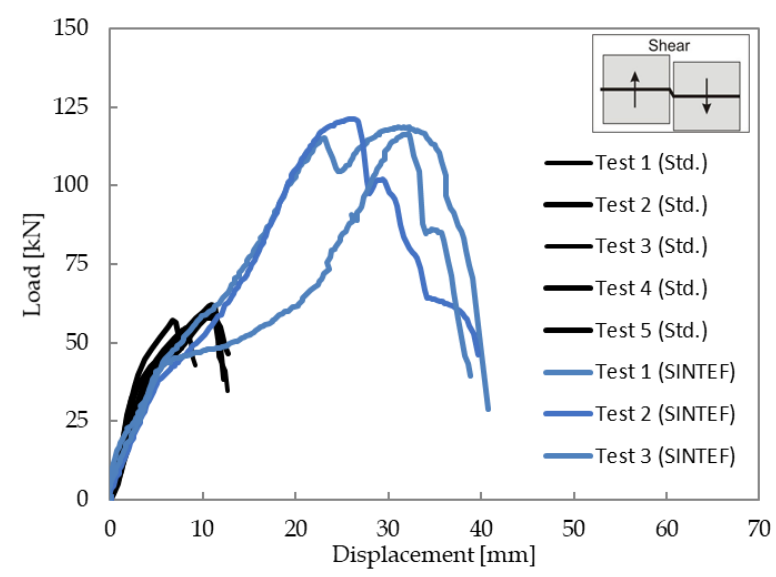

Figure 14. Comparison of shear test results for the Hydrabolt $29 \mathrm{~mm}$, load displacement plot, for standard shear test and SINTEF/NTNU shear test 

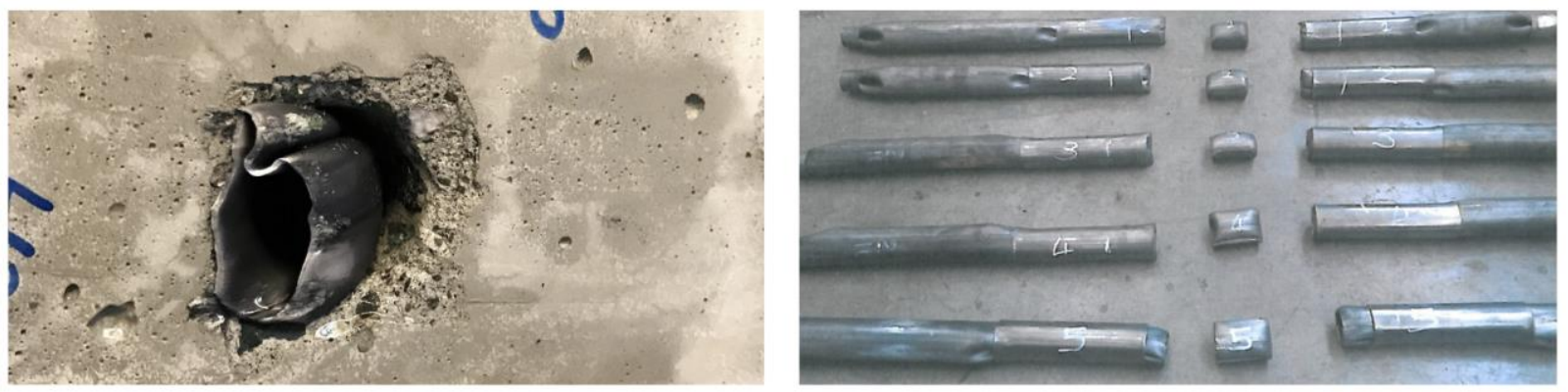

Figure 15. Post-test view of grouted $29 \mathrm{~mm}$ Hydrabolt, SINTEF/NTNU shear test on the left (SINTEF, 2017) and the standard double shear test on the right (CSIR, 2016).

\section{DISCUSSION AND ANALYSIS}

\section{Comparison of pull test results (Standard direct pull test - SINTEF/NTNU test)}

The tensile tests performed in the SINTEF/NTNU rock bolt testing rig can be approximated using a steel tube with a rock bolt installed in either resin or grout. The real benefit of the SINTEF/NTNU apparatus is its ability to better simulate a bolt hole like that in which the rock bolt will be installed in underground. Since the bolt hole used in the test is drilled into the concrete blocks, the roughness of the actual borehole is similar to the borehole underground. Another advantage of this test method over the standard test method is the fact that it is easier to simulate the actual transverse stiffness (ASTM, 2008) of an actual bolt hole.

While this may not have a significant impact on the test results of a fully encapsulated rock bolt, it can significantly impact the performance of a rock bolt that relies on some form of friction, or mechanical anchoring. In such cases, the SINTEF/NTNU testing method is potentially a more accurate representation of what will be experienced underground.

\section{Comparison of shear test results (Standard direct shear test - SINTEF/NTNU test).}

The maximum loads and displacements of the bolts are quite different when comparing the results of the two shear test methods. Earlier shear tests carried out by Stjern in 1995, show the same trend. The higher capacities found by the SINTEF/NTNU full-scale test rig, may be explained by the crushing of the concrete host blocks and the grout, which facilitates bending of the bolt shank and gives almost pure tensile stresses in the bolt at failure (Stjern, 1995). When interpreting the shear capacities of the bolts, the influence of the shear resistance from the joint was not taken into account. The bolt can give a wedge effect to the planes, forcing the surfaces apart and hence suspend the shear contribution from the joint when the bolt is drawn into the joint (Stjern, 1995).

In the standard shear tests as performed above, the shearing load applies somewhat of a guillotine effect on the bolts. The shear capacity results found from pure shear tests carried out in the guillotine jig can be regarded as a minimum bolt shear capacity (Stjern, 1995). The failure surfaces of the ruptured bolts tested in the full-scale rig are more comparable to bolt failures seen in-situ than those from the guillotine tests (Stjern, 1995) as can be seen in Figure 16. Shear failure of rock bolts underground is rarely a pure shear failure of a guillotine type. This is the value of this type of testing procedure.

If a rock engineer were to design for the shear capacity (Load and displacement) based on the shear test results of the standard test, a more extensive (and expensive) support system may be required compared to a potentially more cost-effective support system based on results from the SINTEF/NTNU test rig.

The SINTEF/NTNU testing procedure has other benefits. One such benefit being when the material used to install/test the rock bolt can be designed to approximate the host rock in which the rock bolt 
will be used. Another benefit is associated with the testing procedure is the ability to test a combination of tensile and shear loading in a single test (Yu Chen, 2014).

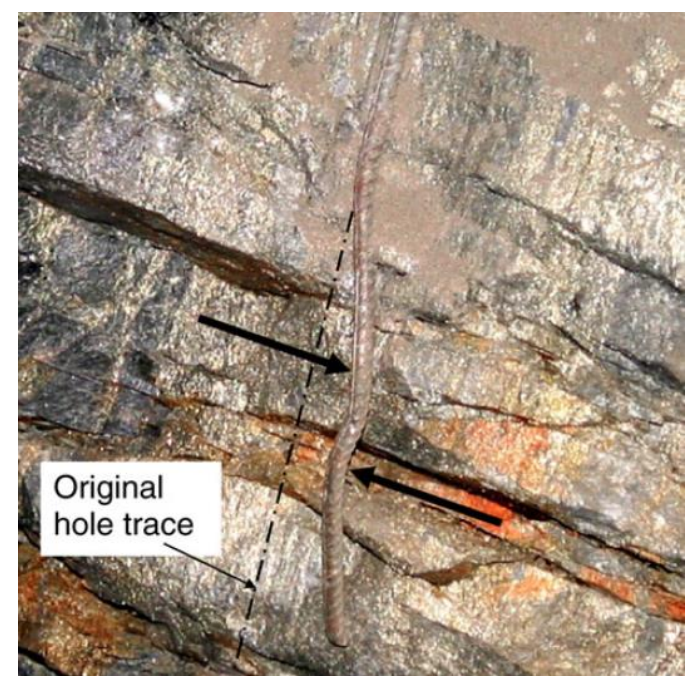

Figure 16. A rebar bolt exposed on the advance face of a cut-and-fill mine stope. The bolt was subjected to shear loads and deviated from its original hole trace. The thick arrows point the direction of possible shear movements in the rock $(L i, 2009)$.

\section{CONCLUSION}

A brief summary of test results and findings: from the comparison of test methods:

- The pull test capacities resulting from SINTEF/NTNU and Standard tests are quite similar for this type of bolt.

$\circ$ SINTEF/NTNU mean maximum load and displacement of $236 \mathrm{kN}$ and $164 \mathrm{~mm}$.

- The standard pull test mean maximum load and displacement of $227 \mathrm{kN}$ and $160 \mathrm{~mm}$.

- SINTEF/NTNU test gave higher shear test capacities than the standard shear test.

- Both load and displacement are higher.

- For the Par1 $25 \mathrm{~mm}$ fully grouted energy-absorbing bolt the maximum load ratio was 1.2 and the displacement ratio was 2.8 between the two test methods.

- For the Hydrabolt $29 \mathrm{~mm}$ inflatable bolt the maximum load ratio was 2.0 and the displacement ratio was 3.7 between the two test methods.

- The higher test results may be due to the fact that the loading is not purely shear, and a tensile contribution is present, but this varies with the type of bolt and bolt design ( $\mathrm{Li}$, 2010)

- SINTEF/NTNU test produces a better representation of reality compared to standard direct tests.

- Bolt is installed in simulated hard rock conditions

- Standard shear tests are more suitable to measure the bolt material minimum shear capacity of a bolt used underground. 


\section{ACKNOWLEDGEMENTS}

Thanks to chief scientist and Professor II Eivind Grøv at SINTEF/NTNU for helpful suggestions regarding this paper.

\section{REFERENCES}

ASTM, 2008. Standard Test Methods for Laboratory Determination of Rock Anchor Capacities by Pull and Drop Tests. D7401.

Li, C.C. 2009. Field Observations of Rock Bolts in High Stress Rock Masses. Rock Mechanics and Rock Engineering (July 2009).

Li, C.C. 2010. A new energy-absorbing bolt for rock support in high stress rock masses, International Journal of Rock Mechanics and Mining Sciences, 47 (3) (2010), pp. 396-404.

CSIR, 2016. Shear testing of five Hydrabolt assemblies (Ø29 mm SAE1010, 1.8 wall thickness). Certificate No.: T24358. CSIR, Johannesburg, South Africa.

CSIR, 2016. Shear testing of five grout bar capsules. Certificate No.: T24529. CSIR, Johannesburg, South Africa.

CSIR, 2015. Test of ten bolts (20mm PAR1 Resin Bolts). Certificate No.: T23352. CSIR, Johannesburg, South Africa.

SINTEF, 2017. Full Scale Rock Bolt Testing: Testing of strength and deformation properties of rock bolt type Hydrabolt 29 mm. Report No. 2017:00004. SINTEF, Trondheim, Norway.

SINTEF,2017. Full Scale Rock Bolt Testing: Testing of strength and deformation properties of $25 \mathrm{~mm}$ Par1 rock bolts. Report No. SBF2017F0007. SINTEF, Trondheim, Norway.

SINTEF, 2016. Full Scale Rock Bolt Testing: Testing of strength and deformation properties of Mp1 and Par1 bolts. Report No. SBF2016F0470. SINTEF, Trondheim, Norway.

Stjern, G. 1995 Practical Performance of Rock Bolts. Doctoral thesis, University of Trondheim, Norway.

Chen, Y.2014 Experimental study and stress analysis of rock bolt anchorage performance, Journal of Rock Mechanics and Geotechnical Engineering 6 (2014) 428-437. 


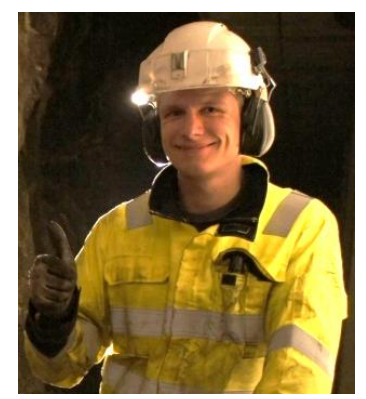

\section{Simon Alexander Hagen}

Senior Rock Technician, Rock and Soil Mechanics SINTEF AS

Educated Laboratory Technician and College Engineer in Rock Engineering with 10 years of experience in Rock Mechanics laboratory and field test methods. 